\title{
\#EdTechHub
}

\section{Back-to-School Campaigns Following Disruptions to Education}

Rachel Chuang, Tom Kaye, Caitlin Moss Coflan, Björn Haßler

June 2020

For enquiries please email helpdesk@edtechhub.org.

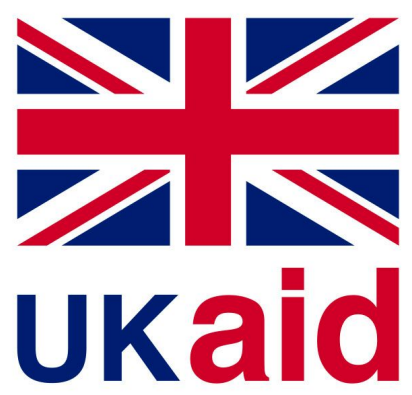

from the British people 


\section{About this document}

Recommended Rachel Chuang, Tom Kaye, Caitlin Moss Coflan, Björn Haßler (2020).

citation. Back-to-School Campaigns Following Disruptions to Education. (EdTech Hub Helpdesk Response No 12). Available under Creative Commons Attribution 4.0 International, https://creativecommons.org/licenses/by/4.0/.

Licence. Creative Commons Attribution 4.0 International

https://creativecommons.org/licenses/by/4.0/.

You - dear readers - are free to share (copy and redistribute the material in any medium or format) and adapt (remix, transform, and build upon the material) for any purpose, even commercially. You must give appropriate credit, provide a link to the license, and indicate if changes were made. You may do so in any reasonable manner, but not in any way that suggests the licensor endorses you or your use.

Identifiers. $\quad$ 2405685:DS66UGW4; DOI: $10.5281 /$ zenodo.3878423

Internal use. g/d/1xd0tB3xhoo61PiuaFQruZPLC4Ha8l8Z3PKcfwCK b0I

Version 1

2020-06-04

This material has been funded by UK aid from the UK government; however the views expressed do not necessarily reflect the UK government's official policies. 
1. Introduction $\quad 4$

2. Return to school campaigns following disruptions 5

Radio 5

Television 5

Mobile phones 5

Internet 6

$\begin{array}{ll}\text { 3. Focus areas } & 7\end{array}$

3.1. Start planning early and align actors $\quad 7$

Figure 1. Actors involved in school reopenings and promoting safe schools (Theirworld, 2018).

3.2. Establish regular communications with the local community 8

3.3. Work with schools to set up sanitation and safety procedures 8

3.4. Support students physically, mentally, and financially 9

3.5. Focus on marginalised learners 9

3.6. Equip teachers with support and curriculum materials 10

4. COVID-19 accelerated funding and back-to-school strategies 11

Figure 2. Mapping key elements of back-to-school strategies to GPE funding proposals (Global Partnership for Education, 2020c). Sources: COVID-19 Accelerated Funding Applications from Ghana, Malawi, Mozambique, Rwanda, and Zambia.

Figure 3. Back to school activities outlined in GPE funding proposals (Global Partnership for Education, 2020c). Sources: COVID-19 Accelerated Funding Applications from Ghana, Malawi, Mozambique, Rwanda, and Zambia. 


\section{Introduction}

The COVID-19 pandemic has resulted in the largest disruption to schooling since the second world war. At the peak of its impact on education systems, schools were closed in nearly 200 countries with almost 1.5 billion learners affected (UNESCO, 2020).

Countries have moved quickly to respond to this crisis. Technologies including print, radio, television, phones, and online have been leveraged to support learning. This has helped to ensure some continuity of education during the pandemic.

While distance education may help limit COVID-19's negative impact on learners, it is no substitute for school-based education. Recent modelling from the US indicated that three months of school closures may result in learners losing a whole year of learning gains (Tarasawa, 2020). The ramifications in countries where distance learning systems are less robust may be significantly worse.

School closures in low- and middle-income countries are expected to have long-term negative impacts, including increased inequality and decreased health outcomes (UNESCO, UNICEF, World Bank \& WFP, 2020). The impact of school closures will be particularly damaging for marginalised students, who are already less likely to be in school. These groups face additional risk factors from being out of school, including violence, sexual abuse, being integrated into child labour schemes, and stress and anxiety. Ensuring children rapidly return to school as soon as it is safe and practical is a crucial next step in supporting children's learning and life outcomes in these contexts.

This document expands upon guidance and evidence kits developed by the WHO, WFP, Center for Global Development, and IASC Global Education Cluster and Child Protection Global Protection Cluster. Specifically, key themes of effective school re-openings are examined in the context of modalities used to deliver distance learning (e.g., radio, television) and mapped to proposals from the Global Partnership for Education's first round of COVID-19 funding. 


\section{Return to school campaigns following disruptions}

While the disruption caused by COVID-19 is significant, there have been other disruptions to schooling in a wide range of countries over past decades. Some disruptions have been regional (e.g., those caused by Ebola between 2013 and 2016 and the Asian financial crisis between 1997 and 1999). Other disruptions have been country specific (e.g., civil wars, natural disasters, etc.). This section analyses return-to-school campaigns from past years to examine how the modalities that countries are using to deliver distance education have been leveraged to support back-to-school campaigns.

\section{Radio}

In 2015, during the Ebola epidemic, solar radios were distributed to communities in Guinea by UNICEF. In parallel, radio stations broadcasted messages about safety protocols and how to prevent Ebola. Once schools reopened, the Ministry of Education broadcasted messages about the start of the school year through 28 radio stations (Interagency Collaboration on Ebola, 2015).

Ghana recently received funding from the Global Partnership for Education (GPE) to support its COVID-19 response. The proposal highlighted a back-to-school strategy that utilised radio and TV to publicise health, safety and the importance of returning to school. The campaign will be launched across 16 regions within 60 days of schools reopening (Global Partnership for Education, 2020a).

Household radio ownership rates vary significantly across countries (e.g., $1 \%$ in Bangladesh to $85 \%$ in Bolivia) (Dreeson et al., 2020). However, it is possible that radio instruction can be accessed through other devices, such as via mobile phone or television channels. Limited data is available on the usage of smartphones to listen to radio across LMICs. The value of radio instruction depends on the availability of radios across households, as well as the prevalence of accessing radio content on non-radio devices.

\section{Television}

In 2015, the International Organization for Migration (IOM) and the National Guinean Theater Association produced a television mini-series in response to Ebola. The mini-series was used as a discussion tool in local communities in Guinea to educate people about Ebola and reduce stigma against survivors (Interagency Collaboration on Ebola, 2015). In Liberia, UNICEF delivered messaging about Ebola through community cinema nights for individuals that did not have a television at home (Inveneo, 2014).

\section{Mobile phones}

DFID and the Sierra Leone Ministry of Education partnered with local communities to collect monthly updates from schools. From these updates, they identified where there was support to reopen after the Ebola epidemic. SMS messaging was a cheap and easily scalable option for both one-way and two-way communication between actors. Phones were used to send messages both to raise awareness and to identify concerns from the 
community. Information shared via SMS was integrated into the government's data collection system (Berry, 2015; Davis \& Berry, 2020).

\section{Internet}

In 2017, Lebanon's Ministry of Education and Higher Education deployed a back-to-school campaign focused on 'school heroes.' The community celebrated students, teachers, parents, bus drivers, and others committed to education (UNICEF, 2017). The campaign highlighted the role of each community member in enabling access to education for all children. Videos on school heroes were shared on social media platforms with the support of local influencers. A telephone hotline was also set up to respond to school enrollment questions from parents and caregivers (UNICEF, 2017). 


\section{Focus areas}

Safety concerns, financial burdens, and limited support for marginalised learners may lead to a slow return to previous rates of enrollment even after schools are reopened (Tounsi, 2018; Giannini, Jenkins \& Saavedra, 2020). Back-to-school campaigns must address each of these demand-side barriers to education. Supply-side constraints such as teacher attendance, school readiness to resume functions, and the ability of the school to ensure student safety should also be addressed.

This section highlights six key areas programme designers and policy-makers should consider when implementing return-to-school campaigns. The section also looks briefly at other back-to-school campaigns that have received funding through the GPE COVID-19 accelerated funding round.

\subsection{Start planning early and align actors}

Planning for school reopenings should begin as soon as possible (Giannini, Jenkins \& Saavedra, 2020). A detailed plan outlining communication channels, content, and timelines should be created in partnership with all relevant Ministries (e.g., Education, Health, Finance, etc.). Other actors that may be involved include national governments, international organisations, NGOs, CSOs, business, and academia (see Figure 1) (Theirworld, 2018).

Figure 1. Actors involved in school reopenings and promoting safe schools (Theirworld, 2018).

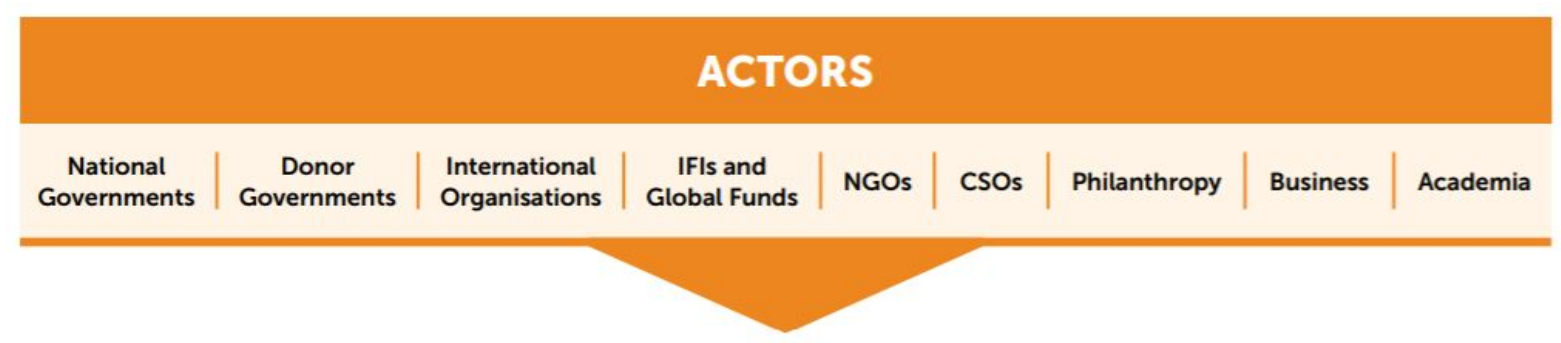

Widespread alignment and transparency is necessary to ensure a unified response to school disruptions. Coordination among actors allows for buy-in and collective decision-making on back-to-school initiatives and timing. It can prevent mixed messaging to learners, parents and families about returning to school. High involvement from community support groups and school committees can positively impact the return-to-school process. These groups can support data collection and facilitate interaction with parents who may be hesitant to send their children to school (UNICEF, 2013). For example, youth community groups in Sierra Leone played an important role in monitoring Ebola cases and improving educational responses (Berry, 2015). Raising awareness about the plan can also help build confidence in school reopenings.

For governments weighing decisions on school reopening, one useful tool is a framework developed by UNESCO, UNICEF, World Bank and WFP. The framework covers three major areas: 
1. why reopen schools,

2. when, where and which schools to reopen, and

3. how to reopen schools.

Prior to reopening, governments must weigh the risks associated with school reopenings against the value of returning to classroom-based lessons.

\subsection{Establish regular communications with the local community}

Open communication with families, teachers, students, local authorities and communities is required to ensure that all stakeholders feel informed about and comfortable with the return-to-school process. For example, if parents are concerned about their children's health and safety it is unlikely that they will send their children to school. Understanding and addressing barriers to school attendance and feedback from parents and caregivers is necessary (Giannini, Jenkins \& Saavedra, 2020).

During 2018, in the Democratic Republic of Congo (DRC), parents were wary of sending their children to school where they could contract Ebola. In response, UNICEF established an information campaign to equip school principals and teachers to answer questions and hesitations from parents. Educators learned about the virus, prevention tactics, and how to raise awareness in the community while limiting panic (Daems \& Willemot, 2018).

Activities that might be used to communicate back-to-school messaging can also include:

- home visits by teachers (while maintaining social distancing),

- local community parades,

- sports, music, poetry, art and drama competitions, and

- shows by local performance groups (UNICEF, 2013).

In 2002, UNICEF encouraged children and teachers in Afghanistan to return to school through a national campaign. The strategy included radio messages, street drama, community meetings, and thousands of posters, stickers, and banners (UNICEF, 2013).

\subsection{Work with schools to set up sanitation and safety procedures}

Schools must be sufficiently cleaned and disinfected prior to reopening, to both protect students and to address parents' concerns. In Sierra Leone, over 36,000 hand-washing stations were distributed prior to the reopening of schools. Similarly, in Guinea, new sanitation infrastructure and latrines were upgraded in 850 schools (World Bank, 2015). In Liberia, students had to wash their hands in chlorinating water and have their temperatures measured prior to entering the classroom (Watt, 2020).

Beyond hygiene and sanitation, it is necessary to ensure appropriate social distancing even after schools reopen. Reorganisation of the school day, such as double-shifting and blended learning approaches, is recommended (International Institute for Educational Planning, 2020). Double-shifting will reduce overcrowding and may prevent transmission of COVID-19. Alternatively, blended learning could be used to combine 
in-person instruction with remote coursework. Students can attend school for part of the day and complete coursework at home through the use of various modalities.

\subsection{Support students physically, mentally, and financially}

During the COVID-19 pandemic, students and families may experience multiple types of burdens and stressors. The back-to-school strategy should address the physical, mental, and financial needs of students recovering from the aftermath of the pandemic.

Within the community, schools can provide essential services, including food. Establishing a feeding programme will counter malnutrition and serve as a financial incentive to send children back to school (Global Business Coalition for Education, 2014). School feeding programmes can establish a sense of routine for the families while allowing parents time to grieve, recover and find employment (Briggs, 2018).

Supporting the socio-emotional wellbeing of students and teachers is important (Giannini, Jenkins \& Saavedra, 2020). Where possible, non-essential tests / exams should be waived to reduce stress for students (UNESCO, UNICEF, World Bank, \& WFP, 2020). For students who have experienced trauma or life events as a result of COVID-19, governments should provide psychosocial and child protection services (Global Business Coalition for Education, 2014). For example, in 2015, various organisations provided mental health and other support services to Liberians affected by Ebola. Plan International, in partnership with the Ministry of Gender and Social Protection and UNICEF, conducted sessions on trauma healing for families (Interagency Collaboration on Ebola, 2015).

Parents may not be able to afford tuition fees after the outbreak due to loss of jobs or time spent in quarantine (Watt, 2020). Governments should make adjustments accordingly to encourage student attendance. In response to the Ebola epidemic, the government of Sierra Leone waived examination fees and subsidised secondary school fees for two years (World Bank, 2015). Other incentives encompass providing school uniforms and offering scholarships for children who are most at risk of not returning to school (UNICEF, 2013).

Any campaign should leverage COVID-19-related activities being undertaken in other sectors. For example, educational materials can be packaged with existing food and health supplies for widespread distribution. A back-to-school campaign should additionally last more than a few weeks, given that some students may not return right away. Students taking on jobs to support their families can require further incentives (e.g., cash transfers) or may need to access school via flexible modalities or time requirements.

\subsection{Focus on marginalised learners}

The most vulnerable and marginalised groups (e.g., girls, children with disabilities, ethnic and religious minorities) should be prioritised in a back-to-school strategy. These students are often disproportionately affected by having to move to remote learning, as remote learning has generally been found to be more successful among students from higher socio-economic segments. Schools should provide targeted support to these learners to ensure they return to school, including identifying and removing barriers to 
school entry. Initiatives can include flexible learning approaches and provision of scholarships (Giannini, Jenkins \& Saavedra, 2020).

Girls and young mothers must be encouraged, not barred from returning to school. Social media platforms and virtual safe spaces can be created for girls with access to mobile phones. To reach the most marginalised girls, safe, in-person encounters may be required (Naylor \& Gorgen, 2020). Campaign messaging should be tailored to the local context and counter harmful gender norms (lenkins \& Winthrop, 2020). For example, the shutdown of school systems during the Ebola epidemic led to a significant increase in teenage pregnancies and gender-based violence. After the epidemic, when schools reopened, pregnant girls in Sierra Leone were banned from school (Watt, 2020). In recent months, Sierra Leone has issued a policy that will allow pregnant girls to return to school with other students (Jenkins \& Winthrop, 2020).

The campaign should additionally target individuals who were out of school prior to the COVID-19 pandemic. Rejoining a class may be easier for these students, given that all students will be re-acclimating to the classroom (UNESCO, UNICEF, World Bank, \& WFP, 2020).

\subsection{Equip teachers with support and curriculum materials}

Providing teachers with guidance on COVID-19 can be an important factor in combating outbreaks. Teachers can effectively share information with students and their families through community events on symptoms and ways to prevent infection. In Nigeria, after Ebola was contained, at least two faculty members from every school were trained on Ebola prevention measures (Global Business Coalition for Education, 2014). The Guinea Ministry of Education redesigned teacher education programmes to include lessons on Ebola and related issues, benefiting over 12,000 teachers (World Bank, 2015).

Teachers and local education staff must be engaged through guidance and materials on effectively addressing learning gaps (UNESCO, UNICEF, World Bank, \& WFP, 2020). In 2015, Liberia provided 15,000 teachers with curriculum refresher sessions following the Ebola outbreak (World Bank, 2015). ICT can further supplement a framework of teacher practices by enabling virtual coaching and setting up peer networks through platforms such as WhatsApp, Skype, and Telegram (Haßler, Allier-Gagneur, McBurnie, \& Damani, 2020).

A range of OER materials for teacher support are available. For example, OER4Schools serves as a professional learning resource for teachers and is freely available. The resource covers interactive teaching principles through YouTube videos and online materials that can be downloaded as pdfs for offline usage (University of Cambridge, 2015). Open textbooks and teacher guides are also available. Siyavula, an organization based in South Africa, offers free downloads of Mathematics and Science textbooks and lesson plans for use by students and teachers (Siyavula, 2020). In India and Sri Lanka, textbooks can be downloaded directly from the Ministry of Education websites (Educational Publications Department, 2015; National Council of Educational Research and Training, 2020). 


\section{COVID-19 accelerated funding and back-to-school strategies}

As of June 1, 2020, GPE has awarded USD 125 million in grants in response to COVID-19 to support education in 10 countries. There are 40 proposals currently under review. In response to high demand, GPE has increased its COVID-19 emergency fund to USD 500 million (Global Partnership for Education, 2020b; Global Partnership for Education, 2020g).

In addition to developing remote learning programming, grants will cover back-to-school strategies. Figure 2 analyses back-to-school initiatives embedded in the first set of funding proposals for Ghana, Malawi, Mozambique, Rwanda and Zambia. The proposals, totaling USD 60 million, were approved by GPE between April 28 to May 15, 2020 (Global Partnership for Education, 2020c; Global Partnership for Education, 2020g). These plans, elaborated in more depth in Figure 3, provide examples of how countries have addressed each of the six focus areas for back-to-school initiatives outlined above.

Figure 2. Mapping key elements of back-to-school strategies to GPE funding proposals (Global Partnership for Education, 2020c). Sources: COVID-19 Accelerated Funding Applications from Ghana Malawi Mozambique, Rwanda, and Zambia.

\begin{tabular}{|l|c|c|c|c|c|}
\hline & Ghana & Malawi & Mozambique & Rwanda & Zambia \\
\hline Alignment & & $X$ & & $X$ & $X$ \\
\hline Sanitation & $X$ & $X$ & $X$ & $X$ & $X$ \\
\hline $\begin{array}{l}\text { Student support } \\
\text { (physical, mental, } \\
\text { financial) }\end{array}$ & $X$ & $X$ & $X$ & $X$ & $X$ \\
\hline $\begin{array}{l}\text { Marginalised } \\
\text { learners }\end{array}$ & $X$ & $X$ & $X$ & $X$ & $X$ \\
\hline Teacher support & & & $X$ & & $X$ \\
\hline
\end{tabular}

Figure 3. Back to school activities outlined in GPE funding proposals (Global Partnership for Education, 2020c). Sources: COVID-19 Accelerated Funding Applications from Ghana Malawi, Mozambique, Rwanda, and Zambia.

\begin{tabular}{|l|l|}
\hline Country & Proposal activities \\
\hline Ghana & $\begin{array}{l}\text { Develop a radio and TV-based campaign on health, safety, } \\
\text { prevention of gender-based violence and early pregnancy, and } \\
\text { importance of returning to school } \\
\text { N Launch campaign across } 16 \text { regions within } 60 \text { days of schools } \\
\text { reopening; campaign will last for over } 2 \text { weeks }\end{array}$ \\
\hline
\end{tabular}




\begin{tabular}{|c|c|}
\hline & $\begin{array}{l}\text { Develop communications that are child-friendly and accessible to } \\
\text { people in rural areas, with limited literacy, etc. } \\
\text { Sanitise schools, especially those used for emergency response } \\
\text { and treatment of the ill } \\
\text { Target inclusion of children with disabilities and girls } \\
\text { Provide remedial support to low-performing students }\end{array}$ \\
\hline Malawi & $\begin{array}{l}\text { Partner with community groups and mass media to encourage } \\
\text { families to send children back to school } \\
\text { Develop back to school campaign at national and community level } \\
\text { Provide catch up classes to counter learning loss } \\
\text { Ensure that hand-washing facilities are available and children are } \\
\text { instructed to wash their hands regularly at each school } \\
\text { Provide recreational materials to students } \\
\text { Establish protection services and referrals for safe schools }\end{array}$ \\
\hline Mozambique & $\begin{array}{l}\text { Use a Building-Back-Better (BBB) approach to reconstruct } \\
\text { classrooms that were affected by } 2019 \text { tropical storms with sanitary } \\
\text { facilities and inclusive measures } \\
\text { Offer remedial classes and accelerated learning for students who } \\
\text { have fallen behind in their coursework } \\
\text { Launch school feeding and student funds programmes } \\
\text { Provide hygiene kits for girls } \\
\text { Strengthen teacher participation in psychosocial support for } \\
\text { themselves and their students } \\
\text { Restock textbooks in priority schools }\end{array}$ \\
\hline Rwanda & $\begin{array}{l}\text { Partner with local governments and school general assembly } \\
\text { committees to develop campaign } \\
\text { Launch door-to-door campaigns to mobilise parents and } \\
\text { communities to send children back to school } \\
\text { Target districts with }>45 \% \text { of the population below the national } \\
\text { poverty line } \\
\text { Use information from the school data management system } \\
\text { (SDMS) to provide all public schools with a water tank, and grants for } \\
\text { soap and hand-washing equipment } \\
\text { Offer supplemental grants for school feeding and student learning } \\
\text { materials to schools ranked as poorest in the Fifth Integrated } \\
\text { Household Living Survey }\end{array}$ \\
\hline Zambia & $\begin{array}{l}\text { Partner across sectors to conduct back-to-school campaign } \\
\text { Launch community outreach and mobilisation with focus on } \\
\text { safety, hygiene and prevention measures } \\
\text { Orient learners and students on infection prevention practices } \\
\text { Provide select schools with water and solar power } \\
\text { Provide psychosocial support to families, teachers, and students } \\
\text { Provide remedial support to low-performing students } \\
\text { Distribute teaching and learning materials }\end{array}$ \\
\hline
\end{tabular}




\section{References}

Berry, C. (2015). Ebola, Education And Innovation In Sierra Leone. DFID.

https://dfid.blog.gov.uk/2015/09/11/ebola-education-and-innovation-in-sierra-leo nel

Briggs, B. (2018). Safe Schools: getting children back into education after disaster strikes. Theirworld.

https://theirworld.org/news/safe-schools-getting-children-back-into-education-af ter-natural-disaster

Carvalho, S., Rossiter, J., Angrist, N., Hares, S., \& Silverman, R. (2020). Planning for School Reopening and Recovery After COVID-19: An Evidence Kit for Policymakers. Center for Global Development.

https://www.cgdev.org/sites/default/files/planning-school-reopening-and-recover y-after-covid-19.pdf

Daems, T. \& Willemot, Y. (2018). Getting back to normal after Ebola strikes. UNICEF. https://www.unicef.org/stories/getting-back-normal-after-ebola-strikes

Davis, E. \& Berry, C. (2020). Mitigating COVID-19 impacts and getting education systems up and running again: Lessons from Sierra Leone. Global Partnership for Education. https://www.globalpartnership.org/blog/mitigating-covid-19-impacts-and-gettingeducation-systems-and-running-again-lessons-sierra

Dreeson, T., Akseer, S., Brossard, M., Dewan, P., Giraldo, J., Kamei, A., Mizunoya, S., \& Ortiz, J.S. (2020). Promising practices for equitable remote learning: Emerging lessons from COVID-19 education responses in 127 countries. https://www.unicef-irc.org/publications/pdf/IRB\%202020-10.pdf

Educational Publications Department. (2015). Text Books Download. www.edupub.gov.lk/BooksDownload.php

Giannini, S., Jenkins, R., \& Saavedra, J. (2020). Reopening schools: When, where and how? World Bank Blogs.

https://blogs.worldbank.org/education/reopening-schools-when-where-and-how

Global Business Coalition for Education. (2014). Ebola Emergency: Restoring Education, Creating Safe Schools and Preventing a Long-term Crisis. https://gbc-education.org/wp-content/uploads/2014/12/EbolaandEducationRepo rt122014.pdf

Global Partnership for Education. (2020). Ghana COVID-19 Accelerated Funding Application Form.

https://www.globalpartnership.org/sites/default/files/document/file/2020-04-CO VID-accelerated-funding-Ghana\%20Updated\%20Proposal\%20May\%205\%202020 \%20final.pdf

Global Partnership for Education. (2020). Global Partnership for Education increases 
COVID-19 (coronavirus) emergency fund to US\$500 million.

https://www.globalpartnership.org/news/gpe-increases-covid-19-coronavirus-em ergency-fund-us500-million

Global Partnership for Education. (2020). Global Partnership for Education provides $\$ 68$ million in grants for education response to COVID-19 (coronavirus).

https://www.globalpartnership.org/news/global-partnership-education-provides68-million-grants-education-response-covid-19

Global Partnership for Education. (2020). Grant request to finance Rwanda COVID-19 education response from COVID-19 accelerated funding window under the GPE fund. https://www.globalpartnership.org/sites/default/files/document/file/2020-05-11Rwanda-COVID-19-Application 0.pdf

Global Partnership for Education. (2020). Programa de Educação em Emergência 2020-2021 financiado pela Parceria Global da Educação.

https://www.globalpartnership.org/sites/default/files/document/file/2020-05-18COVID-19\%20AFF\%20Request\%20Mozambique.pdf

Global Partnership for Education. (2020). Proposal for GPE Accelerated Funding for COVID-19 Response (Malawi).

https://www.globalpartnership.org/sites/default/files/document/file/2020-05-CO VID-19\%20AFF\%20Request\%20Malawi 0.pdf

Global Partnership for Education. (2020). Response to the COVID-19 (coronavirus) pandemic.

https://www.globalpartnership.org/gpe-and-covid-19-pandemic?location=initial-v iew\#covid-19-grants

Global Partnership for Education. (2020). Zambia COVID-19 Accelerated Funding Application Form.

https://www.globalpartnership.org/sites/default/files/document/file/2020-04-CO VID-accelerated-funding-Zambia-Proposal-April-29-final\%20.pdf

Haßler, B., Allier-Gagneur, Z., McBurnie, C. \& Damani, K. (2020). Characteristics of effective teacher education in low- and middle-income countries: a detailed summary of evidence on teacher education. (EdTech Hub Helpdesk Response No. 10B).

IASC Global Education Cluster \& Child Protection Global Protection Cluster. (2020). Safe Back to School: A Practitioner's Guide.

https://inee.org/resources/safe-back-school-practitioners-guide

Interagency Collaboration on Ebola. (2015). Situation Report No. 11. https://www.humanitarianresponse.info/en/node/114079

Inveneo. (2014). Key ICT Features in UNICEF'S Response to Fighting Ebola. http://www.inveneo.org/2014/11/key-ict-features-in-unicefs-response-to-fightingebola/

International Institute for Educational Planning. (2020). Reopening schools: How to get 
education back on track after COVID-19. UNESCO.

www.iiep.unesco.org/en/reopening-schools-how-get-education-back-track-after-c ovid-19-13424

Jenkins, R. \& Winthrop, R. (2020). 5 actions to help bring the most marginalized girls back to school after COVID-19. The Brookings Institution. https://www.brookings.edu/blog/education-plus-development/2020/05/15/5-acti ons-to-help-bring-the-most-marginalized-girls-back-to-school-after-covid-19/

Linden, T. (2001). Double-Shift Secondary Schools: Possibilities and Issues. https://documents.worldbank.org/curated/en/819151468740107174/pdf/multiop age.pdf

National Council of Educational Research and Training. (2020). Textbook. www.ncert.nic.in/NCERTS/textbook/textbook.htm

Naylor, R. \& Gorgen, K. (2020). Overview of emerging country-level response to providing educational continuity under COVID-19. https://edtechhub.org/wp-content/uploads/2020/05/marginalised-girls.pdf

Siyavula. (2020). Our Work. https://www.siyavulaeducation.com/work-oer.html

Theirworld. (2018). Safe Schools: The Hidden Crisis.

http://s3.amazonaws.com/theirworld-site-resources/Reports/Theirworld-ReportSafe-Schools-December-2018.pdf

Tounsi, S. (2018). Back to school - but classes are empty because of Ebola fears in DRC. Theirworld.

https://theirworld.org/news/ebola-fears-keep-children-off-school-in-drc

UNESCO, UNICEF, World Bank, \& WFP. (2020). Framework for reopening schools.

https://unesdoc.unesco.org/ark:/48223/pf0000373348/PDF/373348eng.pdf.multi

UNICEF. (2013). UNICEF Back-to-School Guide: Evidence-Based Strategies to Resume Education in Emergencies and Post-Crisis Transition.

https://reliefweb.int/sites/reliefweb.int/files/resources/UNICEF Back To School Guide 2013.pdf

UNICEF. (2017). Ministry of Education joins UN in launching Back to School campaign. https://www.unicef.org/lebanon/press-releases/ministry-education-joins-un-laun ching-back-school-campaign

University of Cambridge. (2015). The OER4Schools Professional Learning Resource. https://oer.educ.cam.ac.uk/wiki/OER4Schools

Watt, E. (2020). From Ebola to coronavirus: education must not be forgotten in a health crisis. Theirworld.

https://theirworld.org/news/ebola-to-coronavirus-education-vital-in-health-crisis

WFP, FAO, \& UNICEF. (2020). Mitigating the effects of the COVID-19 pandemic on food and 
nutrition of schoolchildren.

https://docs.wfp.org/api/documents/WFP-0000114175/download/? ga=2.124268 175.448268632.1588682993-1835378179.1587115625

WHO. (2020). Considerations for school-related public health measures in the context of COVID-19.

https://www.who.int/publications-detail/considerations-for-school-related-publichealth-measures-in-the-context-of-covid-19

World Bank. (2015). Back to School After the Ebola Outbreak.

https://www.worldbank.org/en/news/feature/2015/05/01/back-to-school-after-eb ola-outbreak 